\title{
MULTIPLE FLOW RATE MODELLING OF NITRIC OXIDE IN COPD - METHODOLOGICAL CONCERNS
}

\author{
Kay Roy, MRCP*, Zoe Borrill, MRCP*, Andrew Hazel, PhD\#, Jorgen Vestbo, MD* and Dave Singh, MD* \\ *Medicines Evaluation Unit, North West Lung Centre, The University of Manchester, Wythenshawe Hospital, Manchester, UK \\ \#Dept of Mathematics, Manchester University, Manchester, UK
}

WINNING ABSTRACT: Multiple flow rates $\mathrm{Fe}_{\mathrm{NO}}$ data two-compartment mathematical modelling can estimate NO airway wall concentration $\left(\mathrm{Caw}_{\mathrm{NO}}\right)$, airway wall diffusing capacity $\left(\mathrm{Daw}_{\mathrm{NO}}\right)$, alveolar concentration (Calv $\mathrm{NO}_{\mathrm{NO}}$ and maximal NO flux (Jaw $\mathrm{NO}_{\mathrm{NO}}$.

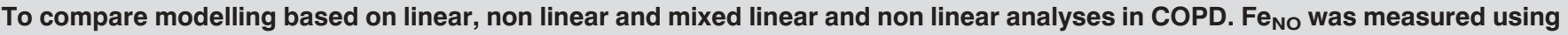
the Niox analyser (Aerocrine) at flow rates: 10, 30, 50, 100 and 200ml/s in 50 COPD patients and the data applied to 4 different methods. All methods showed that current smoking reduced Caw $\mathrm{NO}_{\mathrm{NO}}$. Jaw $\mathrm{NO}_{\mathrm{NO}}$ data differed between methods (Table 1). All the methods showed that current smoking did not affect Calv NO $_{\text {or Daw }}$. Comparison of the methods showed that Calv No $_{\text {and }}$

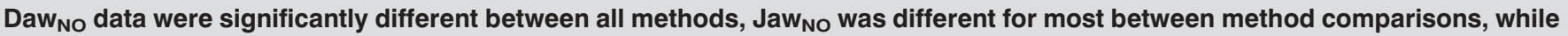
there was agreement between all the methods for Caw NO $_{\text {. Smoking in COPD reduces Caw }}$, but not Calv NO $_{\text {and Daw }}$ NO $_{\text {. Jaw }}$ NO, $_{\text {, }}$

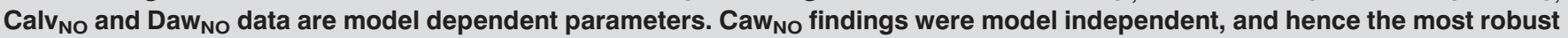
modelled parameter.

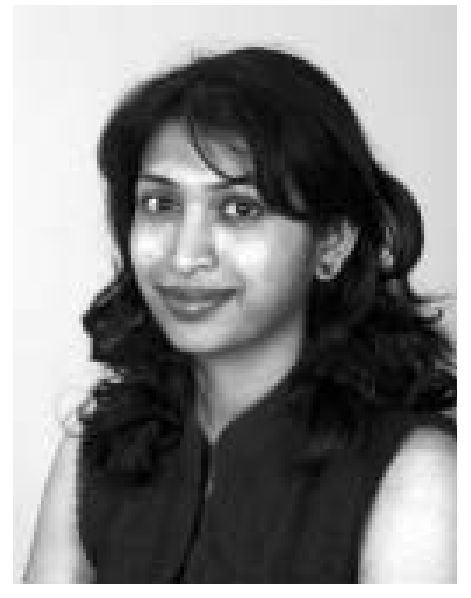

Kay Roy

Research Registrar, Medicines Evaluation Unit, North West Lung Centre, Wythenshawe Hospital, Manchester, UK

\section{MY JOB AND THE UNIT IN WHICH I WORK}

I am currently pursuing a PhD investigating the role of endogenous nitric oxide (NO) in chronic obstructive pulmonary disease (COPD) airway inflammation. By the end of this article, I hope that the importance of this topic will be highlighted and insight provided into the COPD research team which I am a part of in the North West Lung Centre (NWLC), Manchester, UK.

\section{MY WINNING POSTER AS PART OF MY RESEARCH}

In light of our increased awareness of the heterogeneity of inflammatory respiratory diseases, such as asthma and COPD, it is now recognised that different clinical phenotypes of the disease may have different treatment responses. The field of noninvasive biomarkers has developed rapidly over the last few years in the search of easy and effective means of measuring and monitoring inflammatory status, thus allowing the response to treatment to be assessed. This is where NO comes into the story.

Despite the immense amount of work evaluating the role of exhaled nitric oxide fraction $(F \mathrm{e}, \mathrm{NO})$ as a marker of disease control in asthma, there have been markedly fewer studies in COPD. The main reason for not persevering in this disease group could be that initial studies showed that current smoking decreased airway NO levels, and so the results were not as exciting as those in asthmatics. However, looking closely at published data, we thought that there was still a population of COPD patients in whom $\mathrm{Fe}$,NO levels were raised.

The response to corticosteroids in COPD is often poor. This condition is one of the biggest burdens on the health services worldwide, making the need to improve current treatment strategies of great importance. The phenotypic characterisation of COPD would be of value in defining distinct clinical subgroups that may respond differently to interventions.

At the NWLC, I am involved in the phenotypic characterisation of a large cohort of COPD patients, in whom I have also measured $\mathrm{Fe}, \mathrm{NO}$ and $\mathrm{NO}$ metabolites in exhaled breath condensate and sputum supernatant. The aim is to identify a subset with raised levels of $\mathrm{NO}$ and to understand the pathophysiological characteristics of these patients.

The data that was presented at the 2006 European Respiratory Society Congress in Munich was obtained from multiple flow rates of $F e, N O$ applied to a mathematical model in order to estimate concentrations of $\mathrm{NO}$ in the alveolar and bronchial walls of the airways. The location of inflammation in the bronchial tree may influence reponse to treatment; asthmatics with more refractory disease have been found to have higher alveolar concentrations of NO. As with any new technique, a number of methodological issues must be resolved on the path to developing a standardised approach; this is a key area that we have always tackled in our team and that I have addressed in this award-winning abstract which looks at NO modelling. The study was provoked by the fact that there was no gold 


\begin{tabular}{|c|c|c|c|c|}
\hline & Linear 1 & Linear 2 & Nonlinear & Mixed \\
\hline Caw,NO & & CEX: $146.5(101.8-210.6)$ & CEX: 113.9 (79.0-164.2) & CEX: 106.7 (71.5-159.2) \\
\hline Jaw,NO & ${ }^{\#} \mathrm{CS}: 419.9$ (249.6-706.3) & CS: 561.2 (395.4-804.3) & CS: 464.1 (317.3-678.6) & CS: 502.7 (323.8-780.6) \\
\hline
\end{tabular}

CS: chronic obstructive pulmonary disease (COPD) smokers; CEX: COPD ex-smokers; Caw,NO: nitric oxide airway wall concentration; Jaw,NO: maximal nitric oxide flux; N/A: not applicable. Data presented as mean (95\% confidence intervals). ${ }^{\#}$ : Jaw,NO (total flux).

standard method for the modelling of $\mathrm{NO}$ in the airways, yet important conclusions about the anatomical distribution of NO were being drawn by published papers. Our study shows that different modelling methods give rise to different results, underscoring the need to standardise $\mathrm{NO}$ multiple flow rate modelling. We were also able to show that smoking reduced airway wall concentration of $\mathrm{NO}$ and it was this parameter that proved to be the most robust.

Focusing on the molecular aspects, I now aim to investigate the contribution of NO at a cellular level in airway cells. I will study its effects on glucocorticoid pharmacology. With access to cells from lung tissue resection and bronchoscopy specimens, we have ample opportunity to expose cells to NO and explore changes in mediator release, gene expression and, importantly, protein modification. This may answer questions about the roles of modified proteins in disease progression and about drug effects. I hope that my work will initiate sufficient discussion to prompt further research studying the role of NO in COPD.

\section{MY RESEARCH AS PART OF MY WORKING GROUP/ RESEARCH TEAM}

I am only a small part of a much bigger organisation here at NWLC, which houses researchers across the fields of COPD and asthma. Phase 2 and 3 clinical trials are conducted at a new 18-bed unit, the Medicines Evaluation Unit (MEU), which is fully equipped for full pulmonary physiology testing (including plethysmography and impulse oscillometry) and has on-site laboratory and bronchoscopy facilities. Our new state-of-the-art refurbished laboratory is fully set up for tissue culture, immunohistochemisty, flow cytometry, Western blotting and real-time PCR. There are studies of both adaptive and innate immune function currently ongoing in this laboratory.

\section{THE IMPACT OF MY WORK ON CLINICAL OR RESEARCH PRACTICE}

In terms of clinical phenotypic research, as well as the establishment of the COPD cohort mentioned previously, we have developed a sister cohort for asthmatic smokers, again for epidemiological studies and longitudinal follow-up. A key area of interest is the study of biomarkers in sputum and exhaled breath, and their application in clinical trials.

Team members include three postdoctoral scientists and seven $\mathrm{PhD}$ students with support from various clinical and laboratory-based technicians. The COPD team is led by Dr Dave Singh (Senior Lecturer in Clinical Pharmacology and Consultant Respiratory Physician) and Prof. Jorgen Vestbo. Dave Singh's expertise in the design and running of clinical trials combined with its interface with molecular science greatly compliments the internationally recognised work of Jorgen Vestbo in the epidemiology of COPD. Both individuals provide excellent supervision and support for the clinical and laboratory researchers, allowing an extensive level of COPD research to occur from the laboratory to the ward. 